\title{
Multi-level analyses of spatial and temporal determinants for dengue infection
}

\author{
Sophie O Vanwambeke*1, Birgit HB van Benthem², Nardlada Khantikul ${ }^{3}$, \\ Chantal Burghoorn-Maas ${ }^{4}$, Kamolwan Panart ${ }^{3}$, Linda Oskam², \\ Eric F Lambin ${ }^{1}$ and Pradya Somboon ${ }^{5}$
}

\begin{abstract}
Address: ${ }^{1}$ Department of Geography, Université catholique de Louvain, Place Pasteur, 3, 1348 Louvain-la-Neuve, Belgium, ${ }^{2}$ KIT (Koninklijk Insituut voor de Tropen/Royal Tropical Institute), KIT Biomedical Research, Amsterdam, Meibergdreef 39, 1105 AZ Amsterdam, The Netherlands, ${ }^{3}$ Office of Vector Borne Disease Control No.2, 18 Boonruangrit Road, Muang District, Chiang Mai 50200, Thailand, ${ }^{4}$ Institute of Virology, Erasmus University Rotterdam, the Netherlands and 5 Department of Parasitology, Faculty of Medicine, Chiang Mai University, Chiang Mai 50200, Thailand

Email: Sophie O Vanwambeke* - vanwambeke@geog.ucl.ac.be; Birgit HB van Benthem - b.v.benthem@kit.nl;

Nardlada Khantikul - ornardlada@hotmail.com; Chantal Burghoorn-Maas - c.maas@erasmusmc.nl;

Kamolwan Panart - pkamolwan@hotmail.com; Linda Oskam - l.oskam@kit.nl; Eric F Lambin - lambin@geog.ucl.ac.be;

Pradya Somboon - psomboon@mail.med.cmu.ac.th

* Corresponding author
\end{abstract}

Published: 18 January 2006

International Journal of Health Geographics 2006, 5:5 doi:10.1186/1476-072X-5-5

This article is available from: http://www.ij-healthgeographics.com/content/5/l/5

(C) 2006 Vanwambeke et al; licensee BioMed Central Ltd.

This is an Open Access article distributed under the terms of the Creative Commons Attribution License (http://creativecommons.org/licenses/by/2.0), which permits unrestricted use, distribution, and reproduction in any medium, provided the original work is properly cited.
Received: 02 November 2005

Accepted: 18 January 2006

\begin{abstract}
Background: Dengue is a mosquito-borne viral infection that is now endemic in most tropical countries. In Thailand, dengue fever/dengue hemorrhagic fever is a leading cause of hospitalization and death among children. A longitudinal study among 1750 people in two rural and one urban sites in northern Thailand from 2001 to 2003 studied spatial and temporal determinants for recent dengue infection at three levels (time, individual and household).

Methods: Determinants for dengue infection were measured by questionnaire, land-cover maps and GIS. IgM antibodies against dengue were detected by ELISA. Three-level multi-level analysis was used to study the risk determinants of recent dengue infection.

Results: Rates of recent dengue infection varied substantially in time from 4 to $30 \%$, peaking in 2002. Determinants for recent dengue infection differed per site. Spatial clustering was observed, demonstrating variation in local infection patterns. Most of the variation in recent dengue infection was explained at the time-period level. Location of a person and the environment around the house (including irrigated fields and orchards) were important determinants for recent dengue infection.

Conclusion: We showed the focal nature of asymptomatic dengue infections. The great variation of determinants for recent dengue infection in space and time should be taken into account when designing local dengue control programs.
\end{abstract}

\section{Introduction}

Dengue is a mosquito-borne viral infection, now endemic in most tropical countries, and a major public health con- cern [1]. The reasons for the global resurgence of epidemic dengue fever are not fully understood but are related to demographic and societal changes, including increased 
population movements. In Thailand, dengue fever/dengue hemorrhagic fever has been classified a leading cause of hospitalization and death among children [1]. Epidemics of dengue have been reported throughout the country, with large outbreaks in 1987 and 1998 [2,3], and are spreading from Bangkok [4].

Dengue virus is transmitted by Aedes mosquitoes. The container-breeding Aedes (Stegomyia) aegypti (=Stegomyia aegypti of [6], see below) became important following rapid urbanization in the $20^{\text {th }}$ century [5]. Aedes (Stegomyia) albopictus (=St. albopictus of [6]), although having a controversial role in dengue transmission [7], is found in artificial and natural containers in rural and peri-urban areas [5]. Sparse vegetation, low altitude and good transportation routes favor Ae. aegypti over Ae. albopictus [8]. As a result of phylogenetic studies of the mosquito tribe Aedini, Reinert et al. [6] proposed generic status for a number of traditionally recognized subgenera of genus Aedes, including Stegomyia. However, the traditional classification of genus Aedes, with Stegomyia as a subgenus, is used in this paper.

Many factors have been associated with dengue transmission, including urbanization, water storage and inadequate water supply, increase in discarded containers, and population movements [9]. Marked spatial and temporal diversity in dengue incidence indicated the complexity of dengue virus transmission in a school population in Thailand [10].

Changes in dengue incidence over time and space might also be caused by changes in land use. In Thailand, great areas of forest have been cleared for cash crops and orchards; rice fields have been converted into housing in peri-urban areas, potentially increasing the area and conditions suitable for vector breeding. Only a few attempts have been made at linking land cover or spatial features to dengue infection since it was generally accepted that dengue transmission was restricted to urban areas and settlements rather than natural or agricultural environments $[11,12]$. However, prevalence of seropositivity was recently found to be equally high in rural and peri-urban sites, but risk factors have been shown to vary between rural areas and between rural and peri-urban sites [13]. Analyzing land cover and land use is also relevant because of the links between mosquito breeding and land cover [Vanwambeke et al., forthcoming], and people's location in relation to these.

Since passive surveillance is used in Thailand, many infections are missed because of this large proportion of asymptomatic infections. In a prospective cohort study in Thailand, $87 \%$ of the dengue virus infections were sub- clinical [14]. Seropositivity can be used as a marker for dengue infection.

The present study was undertaken to investigate personal, household, and environmental determinants for recent dengue infection and how these vary over space and time. A Geographical Information System (GIS) was used to evaluate determinants related to landscape features such as land cover.

\section{Methods}

\section{Study design}

Three study sites with changes in land cover between 1989 and 2000 were selected based on patterns of change observed on Landsat images and field visits (Figure 1).

- Ban Pa Nai is a rural area in Chiang Mai province with two villages at an altitude of $450 \mathrm{~m}$. The main land use change observed is the intensification of irrigated areas, facilitated by a dam built in 1996 and by the use of dry season crops.

- Ban Pang is a rural site in Lamphun province at an altitude of $380 \mathrm{~m}$. Surrounding a narrow irrigated valley,

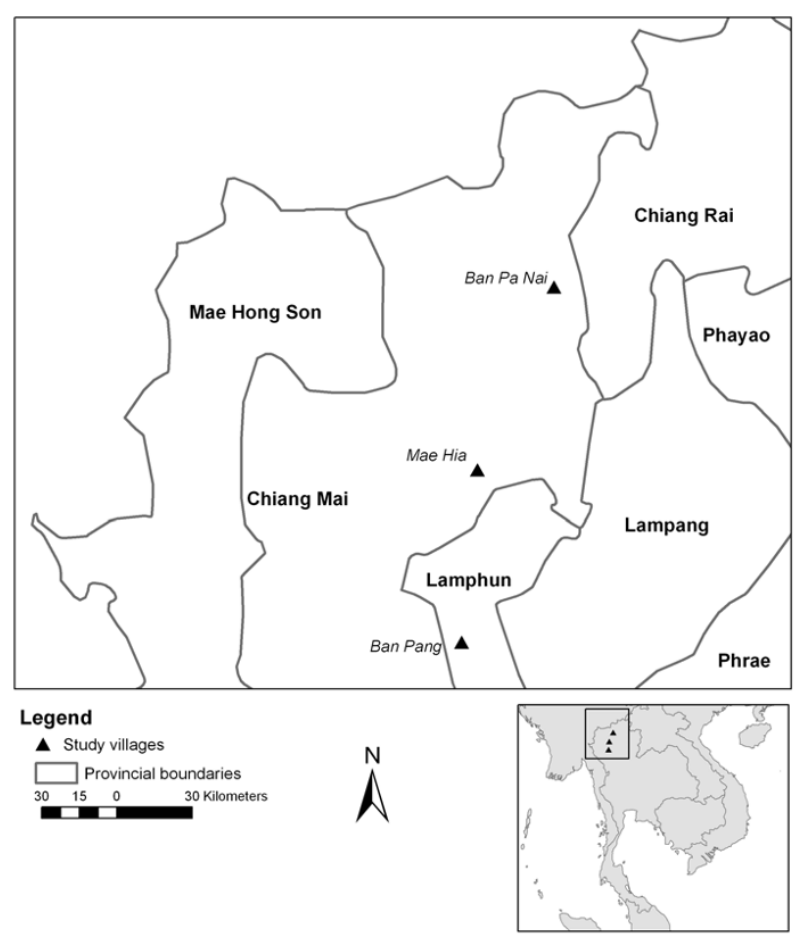

\section{Figure I}

Location of study sites. 
large areas on the hill-slope have been cleared for planting longan trees (fruit cash crop).

- Mae Hia is situated in the suburbs of Chiang Mai and is composed of two villages at an altitude of $320 \mathrm{~m}$. Following land speculation and development, large areas of former rice fields were converted into housing projects or left unused following the Asian financial crisis of 1997.

All study villages had a history of dengue infection recorded by the local public health authorities.

Land cover maps were derived from a March 2000 Landsat image with a spatial resolution of 30 meters using the maximum likelihood classification method, with a global accuracy ranging from $81 \%$ in the heterogeneous periurban Mae Hia to $86 \%$ in Ban Pang and $87 \%$ in Ban Pa Nai. Details on image pre-processing and classification of the image are provided in [15].

Details of the study methodology were described elsewhere [16]. Briefly, the Medical Ethical Committee of Chiang Mai University approved the study, and local permission and collaboration were obtained. Surveys were conducted in May and September of 2001-2003. The latitude and longitude of main points in the village, including street corners, were registered using a hand-held GPS (global positioning system; Garmin GPS II). Households were located on the map along these geo-referenced streets using preliminary hand-drawn maps. The village maps result from a combination of several sources of information and were cross-checked with the topographic map. All spatial data (household maps, land cover maps) were set to the projection of the 1/50000 topographic map of Thailand (Royal Thai Survey Department).

All inhabitants were asked to voluntarily participate in the study. Written informed consent was obtained. Each year between the May and September surveys, participants filled in a calendar registering daily where they spent most of that day. People reported fever subjectively. Finger prick blood was collected on filter paper during the May and September surveys (903 TM Paper, Schleicher\&Schuell, Den Bosch, the Netherlands) and airdried in the shade. Within one or two days, all filter papers were stored in a refrigerator $\left(4^{\circ} \mathrm{C}\right)$ until antibody detection. After reconstitution of the filter papers in phosphatebuffered saline, antibodies were detected using an antidengue IgM capture enzyme linked immunosorbent assay (ELISA) (Focus Technologies, Cypress, CA) [17]. According to the manufacturer of the test, a ratio $>1.0$ is positive; however, many samples had ratios between 1.0 and 1.3, which were considered to be either aspecific reactions or older dengue infections. A ratio of 1.3 or more compared to the reference was therefore considered as seropositive.
In primary dengue infections, the level of IgM antibodies rises shortly after infection and they disappear in most patients two to three months afterwards [18], making them appropriate for studying dengue infection on a seasonal basis. Knowing the relative level of IgG and IgM antibodies is however necessary to distinguish between primary or secondary dengue infections. IgG antibodies can remain present for life but, in a secondary infection, IgM will be relatively more important [19]. Measuring IgM therefore only allows measuring recent dengue infections. A case of dengue infection was defined as a person being IgM-positive after being IgM-negative in the previous survey. Non-cases were defined as persons who remained positive or negative or changed from positive to negative in two consecutive surveys.

Potential individual risk factors were assessed by questionnaire and included demographic factors, knowledge of dengue, location and movements during the day and evening, housing condition factors and use of preventive measures. The same survey methods and questionnaire were used in each site.

\section{Data analysis}

The data presented a nested structure, where individuals are nested within households. Individuals living in the same household share some characteristics, like housing and house surroundings, and are therefore more likely to resemble each other than individuals living in different households. This violates the assumption of independence of observation and can result in spurious significant effects [20]. Moreover, factors at the contextual and environmental level in which the individual is embedded (i.e. household factors) can be significant determinants [21]. Multilevel regression methods were thus chosen for the analysis. These methods allow consideration of withingroup (household) and between-group relations and integration of household and individual-level variables [22]. Since our dependent variable is binary (individual were infected or not), we used the logistic form of the multilevel model. The surveys provided measurements at successive time points for each individual, adding a third level to the data [23], where surveys are nested within individuals. The intraclass correlation (ICC) allows calculation, on an empty model, of the proportion of the total variance explained by the grouping structure, in our case households and individuals. Odds Ratios (OR) and their 95\% confidence interval (95\% CI) were calculated. Factors associated ( $\mathrm{p}$-value $<0.15$ ) with recent dengue infection in univariate analysis were selected for multivariate analysis. In multivariate analysis we tested significant ( $\mathrm{p}$ value $<0.10$ ) interactions between determinants and confounding. In the tables, variables for which the confidence interval does not include one are significant at the 0.05 
level. Variables were mostly categorical, and continuous variables were categorized using quantiles.

Preliminary analysis of the data included several progressive steps. First, analyses of recent dengue infection on individual and household data were conducted survey by survey. Then, two-level multilevel analyses combining individual and household data were conducted per survey and site. The third step consisted of two-level analyses combining longitudinal and individual data, and longitudinal and household data. These analyses were useful in understanding seasonal and inter-annual dynamics and allowed confirmation of the final results. Here we only present the results of the three-level models, with survey, individual and household as the three different levels.

We linked the occurrence of recent dengue infection within a household with the landscape attributes of its surroundings. Based on land cover maps, landscape factors were calculated for each household. The legend of the land cover maps comprised:

1. Mixed deciduous forest.

2. Dry deciduous forest.

3. Bush or sparse forest.

4. Irrigated fields (wet): cultivated in March.

5. Irrigated fields (dry): not cultivated in March.

6. Old orchards (tree cover larger than $60 \%$ ).

7. Water bodies and wide rivers.

8. Upland fields/young orchards (tree cover lower than $60 \%)$.

9. Sparsely vegetated area related to various human activities. No building or agriculture. (e.g. wasteland, grassy area)

10. Densely built areas.

11. Village zones with dense vegetation.

12. Village zones with sparse vegetation.

Variables related to land cover were: (i) the percentage of each land cover class in a 200-meter buffer (circle with a 200 meters radius) around each house; and (ii) the distance between each house and the nearest patch over $2,700 \mathrm{~m}^{2}$ (i.e. at least 4 Landsat pixels) for each land cover class (except village zone classes). The distance from a house to the edge of the village was also calculated. Land cover was considered unchanged over the three years of the study, which was confirmed by field visits in each site and for each year of the epidemiological survey. Landcover variables derived from the 2000 image can therefore be considered valid for the epidemiological survey years, from 2001 to 2003. Variables were categorized using quantiles. No other criterion such as mosquito flight-distance was used.

Furthermore, to investigate whether cases of recent dengue infections were clustered, analyses of clustering in time and in space were performed using the Kulldorff spatial scan statistic [24]. Clustering occurs when the probability of recent dengue infections is not randomly distributed. A circular moving window, with a continuously varying radius, was used to analyze village maps. Similarly, a temporal window was used to analyze the longitudinal data. For each window position, a statistic tested whether there was an increased risk of infection within as opposed to outside the window. The P-value was obtained from a likelihood ratio test based on Monte Carlo simulation with 9,999 replicates. The cluster analyses were performed per village using recent infections as cases and non-infections as controls. Houses were used as census areas. This method only detects circular clusters, which was assumed to be appropriate for the spread of a mosquito-borne disease, and it does account for varying house densities.

\section{Weather impact on dengue}

The weather analysis was limited to deviations in temperature and rainfall of the survey years from the 1989-2003 average, for the following reasons. Weather data were only available for provincial capitals (Chiang Mai and Lamphun), the exact month of infection was unknown and weather variations are not constant between months within a season.

\section{Results}

Details of the study population have been presented before [13]. Briefly, in May 2001, 1928 persons were contacted and 1750 of them were followed-up in September 2001 (91\%), constituting the individuals included in the study. Of these, $28 \%$ were in Ban Pa Nai, $37 \%$ in Ban Pang, and 35\% in Mae Hia. Sex and age distribution differed per site (Table 1). Follow-up rates for the other surveys were $90 \%, 87 \%, 85 \%$ and $81 \%$. Rates of recent infection varied over time and between sites (Figure 2, Table 2). Sex and age distribution of recently infected people also varied over time and between sites (Figures 3 and $4)$. Despite high rates of recent infection in several surveys, the number of cases reported in the calendar filled in daily was low: 6, 5 and 5 cases in 2001, 2002 and 2003, respectively, implying that most infections were asympto- 
Table I: Characteristics of the 1750 participants included in September 2001.

\begin{tabular}{lccccc}
\hline & $\begin{array}{c}\text { Ban Pa Nai } \\
\%\end{array}$ & $\begin{array}{c}\text { Ban Pang } \\
\%\end{array}$ & $\begin{array}{c}\text { Mae Hia } \\
\%\end{array}$ & \multicolumn{2}{c}{ Total } \\
& 28 & 37 & 35 & 1,750 & 100 \\
\hline Total & & & & & \\
Sex & 47 & 48 & 40 & 786 & 45 \\
$\quad$ Male & 53 & 52 & 60 & 964 & 55 \\
$\quad$ Female & & & & & \\
& & & & & \\
Age (years) & 14 & 15 & 13 & 249 & 14 \\
$<15$ & 11 & 19 & 15 & 268 & 15 \\
$15-29$ & 28 & 31 & 24 & 483 & 28 \\
$30-44$ & 25 & 21 & 26 & 420 & 24 \\
$44-59$ & 21 & 14 & 22 & 330 & 19 \\
$>59$ & & & & & \\
& & & & &
\end{tabular}

matic. The data from the district-level public health surveillance system showed 1 case of dengue in Ban Pang in 2001, 1 case in Mae Hia in 2002 and 8 cases in Mae Hia in 2003. Therefore, the percentage of asymptomatic or lightly symptomatic dengue cases (public health systems records divided by recent infection data) varied over the years, ranging from $65 \%$ in 2003 to $99.7 \%$ in 2002 . Although mostly relatively serious cases are reported to the public health authorities, the number of self-reported cases was also low, indicating that these rates are an appropriate estimate.

Since determinants for recent dengue infection differed substantially between sites, results are presented separately by site. The intraclass correlations for household and individual levels were low, indicating that the lowest level of analysis, i.e. time period, explained most of the variance. There was a large variation in human behavior over time.

\section{Ban Pa Nai}

Persons who mostly spent their daytime at school had a lower risk of recent dengue infection compared to other persons (Table 3). Bed nets protected against dengue infection as did houses made of a combination of wood, stone and concrete. Persons who went to the forest during daytime, spent their evening around the house or had dinner after $18.00 \mathrm{~h}$ had an increased risk of dengue infection. People living within $60 \mathrm{~m}$ of irrigated fields had a higher risk of infection. In contradiction with this, households surrounded for more than $40 \%$ by irrigated fields had a two times lower risk.

\section{Ban Pang}

Students, unemployed persons and laborers had a lower risk of dengue infection compared to housewives, farmers and traders (Table 4). Spending daytime inside the house

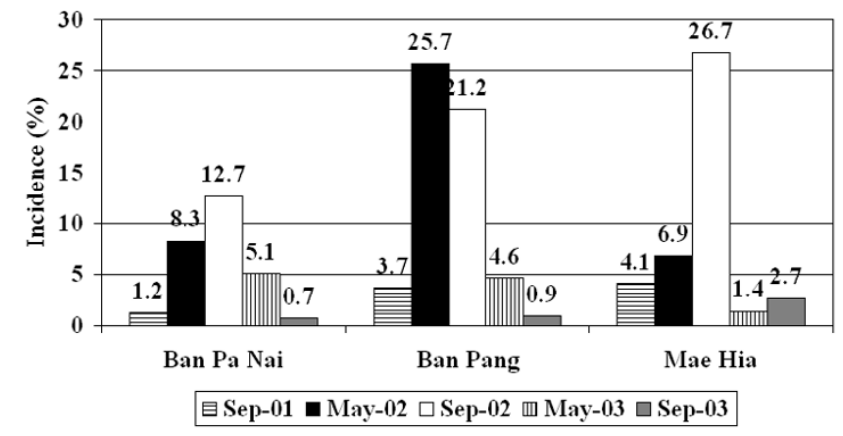

Figure 2

Incidence rate of recent dengue infection.

or in the fields decreased the risk, as did spending the evening inside the house. No important preventive measures were identified. Persons who lived in houses not surrounded by water containers or without domestic animals had a lower risk. In contrast to Ban Pa Nai, persons who lived further away from irrigated fields $(>600 \mathrm{~m})$ had a higher risk. In contradiction with this, persons in households with irrigated fields present within $200 \mathrm{~m}$ had a higher risk than persons living in households with no irrigated fields in the surrounding.

\section{Mae Hia}

People who used abate (a larvicide targeting all mosquito species and other insects) had a higher risk of dengue infection (Table 5). People who reported to be sometimes or often bitten by mosquitoes had a higher risk than people who reported to be never bitten. Persons living in houses made of wood had a lower risk compared to persons living in other houses. People living further away (> $300 \mathrm{~m}$ ) from orchards had a lower risk compared to persons living within $150 \mathrm{~m}$ from orchards. Persons living more than $500 \mathrm{~m}$ from a lake or river or in a part of the village with little vegetation had a higher risk of infection. Persons having bare soils in the surrounding of their house had a lower risk.

The results of the three-level models were consistent with the results of the one and two-level models (results not shown).

Table 2: Number of recent dengue infections over the five surveys.

\begin{tabular}{lcccc}
\hline & Ban Pa Nai & Ban Pang & Mae Hia & Total \\
\hline September 2001 & 6 & 24 & 25 & 55 \\
May 2002 & 39 & 163 & 44 & 246 \\
September 2002 & 59 & 131 & 160 & 350 \\
May 2003 & 23 & 28 & 8 & 59 \\
September 2003 & 3 & 5 & 15 & 23
\end{tabular}




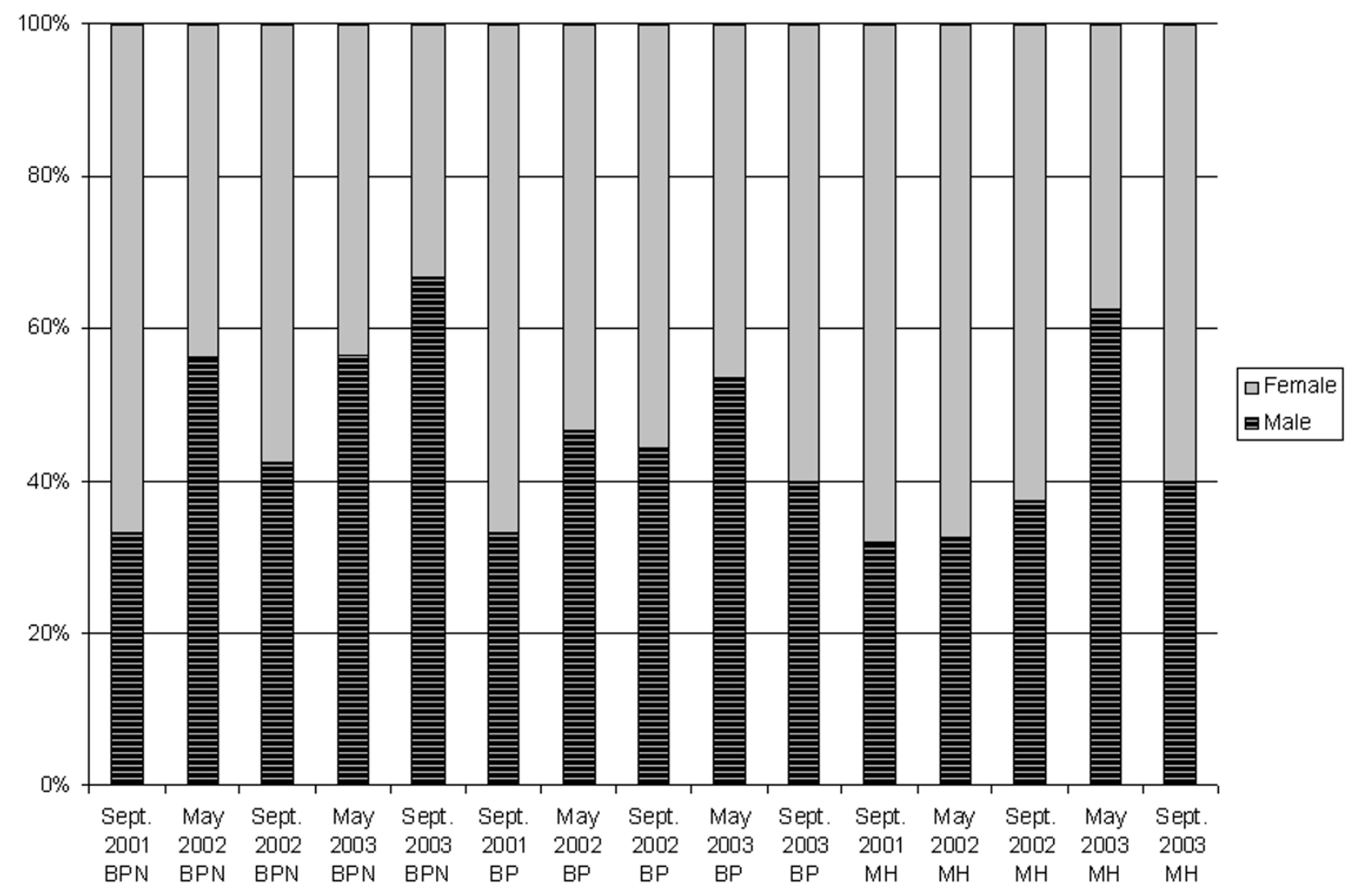

Figure 3

Sex distribution of recently infected individuals. $\mathrm{BPN}=\mathrm{Ban} \mathrm{Pa} \mathrm{Nai} ; \mathrm{BP}=\mathrm{Ban} \mathrm{Pang} ; \mathrm{MH}=\mathrm{Mae} \mathrm{Hia}$.

\section{Cluster analyses}

In all three sites the number of recently infected people was significantly higher in 2002 than in 2001 and 2003 (p $<0.0001$ ), indicating temporal clustering of recent dengue infection. In 2002, there were 72 observed instead of 38.2 expected cases in a spatial cluster in Ban Pa Nai, 274 observed instead of 131.2 expected cases in Ban Pang, and 192 observed against 66.2 expected cases in Mae Hia. Within these temporal clusters, significant spatial clusters were identified: two in Ban Pa Nai, one in Ban Pang and one in Mae Hia (Figure 7). In Ban Pa Nai (Figure 5; only one village and one cluster shown), the most significant cluster was located in the southern part of the village, near the edge of the village, and therefore near irrigated fields, but in this case also near another part of the village. In Ban Pang, the cluster was located in the western end of the village, far from the irrigated fields (Figure 6). In Ban Pa Nai, one other spatial cluster was found in September 2003; 15 cases were observed whereas 4.7 were expected ( $\mathrm{p}=$ $0.004)$.

\section{Weather}

The weather pattern in Chiang Mai and the infection rate were not strongly correlated. In 2001 the temperature of nine months differed significantly from the 1989-2003 average temperature in these months, including six colder months, whereas in 2002 and 2003 this figure was three months (t-test, $\mathrm{p}<0.05$ ), including two colder months each year. For rainfall, 2001 had six months significantly different from the 1989-2003 average rainfall for these months (three months dryer than the average). 2002 had eight anomalous months (three months dryer) and 2003 had seven (four months dryer). 2002 was thus more different in terms of rainfall than in terms of temperature. The largest variations in rainfall are observed in the wet season (May to October). 2002 had extreme rainfall in November and December.

\section{Discussion}

To study the personal, household and environmental determinants of recent dengue infection, and its pattern in 


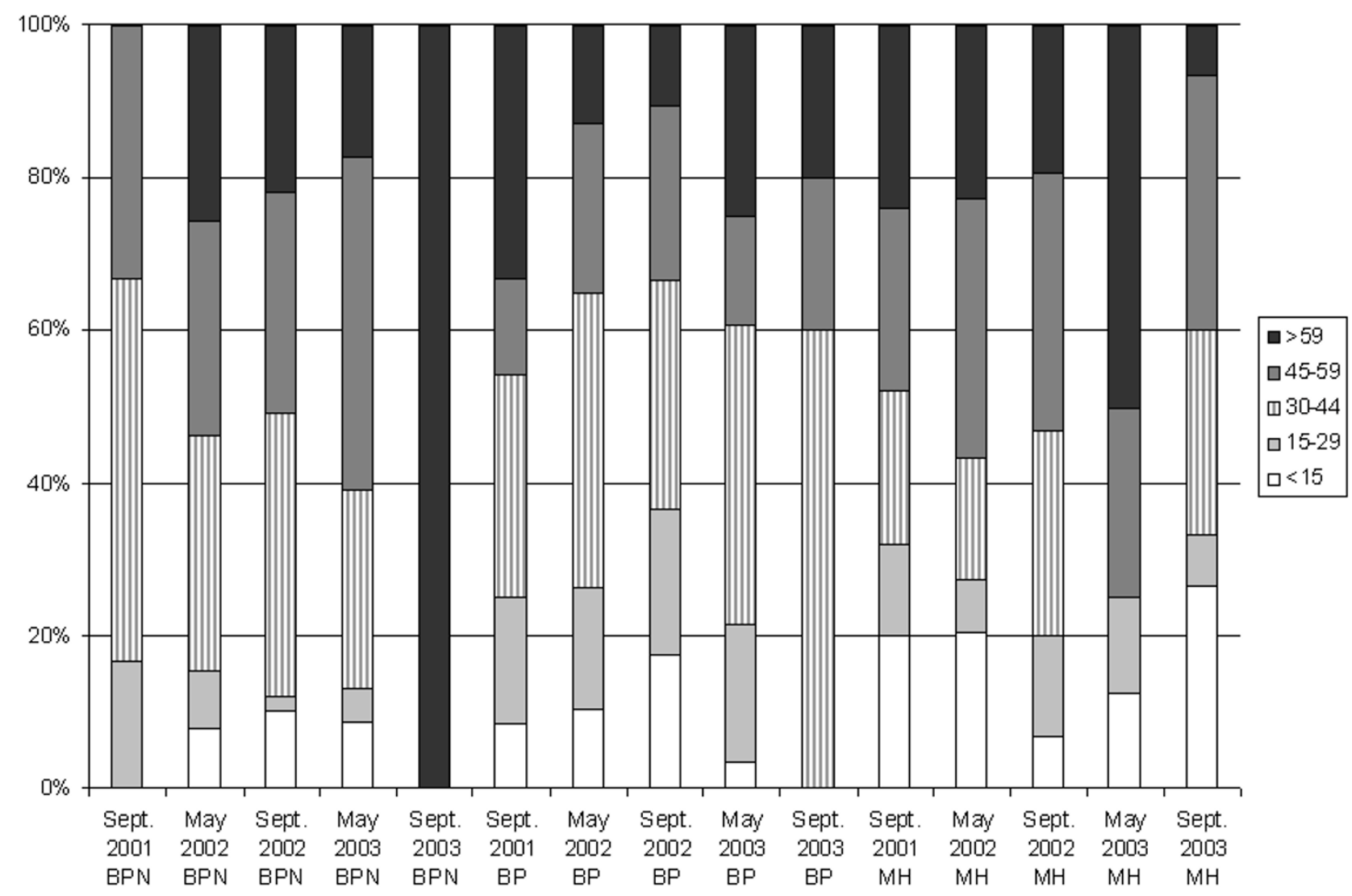

Figure 4

Age distribution of recently infected individuals. $B P N=$ Ban $\mathrm{Pa} N a ; ; B P=B a n$ Pang; $M H=M a e H$ Hia.

space and time, we conducted a prospective cohort study in three dengue-endemic sites in Chiang Mai and Lamphun provinces, Thailand. By following a population biannually during three consecutive years, we located recently infected individuals in space and time by analyzing dengue-specific antibody levels during each survey.

\section{Individual-level risk determinants}

Factors varying over time, that explain the largest part of the variance, included several individual level determinants that were related to the location where people spent their daytime and evenings. In both rural sites, students at school had the lowest relative risk. This possibly relates to the existing intensive prevention programs in and around schools, involving for example breeding site elimination. Being outside the house during daytime or evening increased the risk of dengue infection suggesting that transmission takes place outside the house in rural areas, whereas this was not the case in the peri-urban study site. Eating after $18.00 \mathrm{~h}$ can be associated with activities outside the house taking place later. The identification of clusters of cases in neighboring houses suggests that trans- mission also takes place in or around the house. The decrease in risk associated with days spent in fields is associated with the absence of breeding sites in field cropping areas, whereas days spent in the house, near sources of mosquitoes, increased the risk. The increase in risk associated with the time spent in the forest is not well understood, since Ae. aegypti and Ae. albopictus were not found in the forest in the study area [Vanwambeke et al., forthcoming].

Several studies showed that dengue risk exposure is more important in and around the house because female Ae. aegypti are highly domesticated, and Aedes mosquitoes mostly bite during daytime with pronounced peaks of activity around sunrise and sunset $[25,26]$. Activity can be prolonged at night in urbanized areas, possibly due to the higher light intensity at night [26]. Field observations in our study area, however, suggest that Ae. albopictus is found in villages and in orchards, [Vanwambeke et al., forthcoming], where people could also be infected during peak biting times. Several other studies suggest that $A e$. albopictus probably serves as a maintenance vector of den- 
Table 3: Three-level analyses to identify determinants for recent dengue infection in $\mathrm{Ban} \mathrm{Pa} \mathrm{Nai}$, northern Thailand.

\begin{tabular}{|c|c|c|c|}
\hline & $\% \mathrm{sc}^{\mathrm{a}}$ & $\mathrm{aOR}^{\mathrm{a}}$ & $95 \% \mathrm{Cla}^{\mathrm{a}}$ \\
\hline ICC individuals & & $<0.0001$ & \\
\hline ICC households & & 0.058 & \\
\hline \multicolumn{4}{|l|}{ Time (survey) } \\
\hline May 2002 & 8.3 & 1.0 & \\
\hline September 2002 & 12.7 & 1.60 & $1.01-2.55$ \\
\hline May 2003 & 5.1 & 0.63 & $0.36-1.10$ \\
\hline September 2003 & 0.7 & 0.08 & $0.02-0.27$ \\
\hline \multicolumn{4}{|l|}{ Individual-level variables: } \\
\hline \multicolumn{4}{|l|}{ Spend days } \\
\hline School & 2.5 & 1.0 & \\
\hline House & 6.2 & 3.06 & $1.16-8.08$ \\
\hline Fields & 6.1 & 3.22 & $1.20-8.66$ \\
\hline Forest & 4.8 & 1.97 & $0.19-20.5$ \\
\hline Factory/office & 7.9 & 3.05 & $0.74-12.5$ \\
\hline Other & 5.1 & 2.58 & $0.69-9.65$ \\
\hline \multicolumn{4}{|l|}{ Eat time } \\
\hline$<18.00 \mathrm{~h}$ & 4.4 & 1.0 & \\
\hline$>=18.00 \mathrm{~h}$ & 6.6 & 1.70 & $1.09-2.65$ \\
\hline \multicolumn{4}{|l|}{ Using bednets } \\
\hline No & 8.7 & 1.0 & \\
\hline Yes & 5.3 & 0.43 & $0.24-0.80$ \\
\hline \multicolumn{4}{|l|}{ Days in forest } \\
\hline No & 6.2 & 1.0 & \\
\hline Yes & 12.3 & 1.75 & $0.99-3.07$ \\
\hline \multicolumn{4}{|l|}{ Evening around house } \\
\hline No & 5.6 & 1.0 & \\
\hline Yes & 8.2 & 1.52 & $1.01-2.29$ \\
\hline \multicolumn{4}{|l|}{ Household-level variables: } \\
\hline \multicolumn{4}{|l|}{ Housing } \\
\hline Wood or bamboo & 5.9 & 1.0 & \\
\hline Stone & 7.8 & 1.10 & $0.6 I-2.00$ \\
\hline Combination of stone, wood/bamboo & 4.1 & 0.59 & $0.36-0.96$ \\
\hline \multicolumn{4}{|l|}{ Distance to irrigated fields } \\
\hline $0-60 \mathrm{~m}$ & 7.6 & 1.0 & \\
\hline$>60 \mathrm{~m}$ & 4.3 & 0.45 & $0.29-0.70$ \\
\hline \multicolumn{4}{|l|}{$\%$ of irrigated fields in $200 \mathrm{~m}$} \\
\hline $0-40 \%$ & 6.5 & 1.0 & \\
\hline$>40 \%$ & 4.8 & 0.51 & $0.33-0.78$ \\
\hline
\end{tabular}

a $s c=$ recent dengue infection; $\mathrm{aOR}=$ adjusted Odds ratio; $95 \%-\mathrm{Cl}=$ 95\% Confidence Interval.

gue in rural areas of South-East Asia $[27,28]$. In terms of infection control, this indicates that larval control around houses is relevant, but also that prevention of bites in or around the house could make substantial contribution to the control of infection, as well as similar measures in orchards.

In Mae Hia, being bitten during the day increased the risk of dengue infection, which directly relates to the vector activity. It is however not clear whether this determinant relates to the mosquito population or to the exposure to biting. Also, this variable describes subjective reporting by people, with no distinction between Aedes bites and bites received from other genera or even taxa.

\section{Preventive measures}

In Thailand, dengue control is focused on vector elimination rather than personal protection. The use of abate (a larvicide) in Mae Hia and the use of bed nets in Ban Pa Nai were the only preventive measures related to dengue infection in our study. The use of abate in Mae Hia was actually related to an increase in the risk of dengue infection, suggesting that this preventive measure was applied too late when the larval population had already reached high levels, or was applied incorrectly, for example by not treating all containers. In two villages in North-Eastern Thailand, Eamchan et al. [29] observed only limited success with the use of abate: not all containers were treated or covered. Also, the relationship between the use of preventive measures and disease prevalence is not always straightforward, as was observed by Thomson et al. [30]. The use of bednets in The Gambia was highly correlated to the density of mosquito, whereas the disease prevalence could not easily be related to bednet use. Rosenberg et al. [31] also raised the possibility that, in a village in southeastern Thailand, bednets were used mostly when the risk of infection was low but the nuisance of mosquitoes highest. Information on the level of nuisance caused by mosquitoes or on the observable level of the larvae population, and on the way in which people apply abate in and around their house would help in understanding these results.

The protective effect of bednets in Ban Pa Nai is unexpected when accounting for the fact that Aedes mosquitoes do not bite at night-time. However, it could be related to the early-morning peak of biting activity of Aedes mosquitoes when many people are still in bed. It could also protect children during the day. The potential role of bednets in preventing dengue infection was mentioned by Thavara et al. [32]. It is worth remembering also that many previous studies were focused on urban areas, whereas here the significant preventive effect of bednets was observed in a rural setting. The relation between the use of bednets and other individual or household-level characteristics such as knowledge of dengue was tested but no association was found. Again, more locally-collected information about the timing of activity peaks in mosquitoes, in relation to people's activity timing, would help to interpret the protective effect of bednets. The impact of the use of electric light at night could influence activity times for Aedes mosquitoes [25].

Generally, few preventive measures had statistically significant effects. Their use had even contradictory effects as shown by the case of abate larvicide. This suggests that the timing of prevention is crucial. The use of bednets could 
Table 4: Three-level analyses to identify determinants for recent dengue infection in Ban Pang, northern Thailand.

\begin{tabular}{|c|c|c|c|}
\hline & $\% \mathrm{sc}^{\mathrm{a}}$ & $\mathrm{aOR}^{\mathrm{a}}$ & $95 \% \mathrm{Cla}^{\mathrm{a}}$ \\
\hline ICC individuals & & $<0.0001$ & \\
\hline ICC households & & $<0.0001$ & \\
\hline \multicolumn{4}{|l|}{ Time (survey) } \\
\hline May 2002 & 25.7 & 1.0 & \\
\hline September 2002 & 21.2 & 0.84 & $0.64-1.11$ \\
\hline May 2003 & 4.6 & 0.14 & $0.09-0.21$ \\
\hline September 2003 & 0.9 & 0.03 & $0.01-0.07$ \\
\hline \multicolumn{4}{|c|}{ Individual-level variables: } \\
\hline \multicolumn{4}{|c|}{ Profession } \\
\hline Farmer & 12.6 & 1.0 & \\
\hline Trader & 15.1 & 1.08 & $0.56-2.09$ \\
\hline Housewife & 14.7 & 1.15 & $0.69-1.90$ \\
\hline Student & 9.0 & 0.51 & $0.34-0.77$ \\
\hline Other & 12.8 & 0.55 & $0.26-1.16$ \\
\hline Unemployed & 8.3 & 0.55 & $0.30-0.99$ \\
\hline Labour & 10.0 & 0.63 & $0.43-0.91$ \\
\hline \multicolumn{4}{|l|}{ Days in house } \\
\hline No & 19.8 & 1.0 & \\
\hline Yes & 10.5 & 0.71 & $0.54-0.94$ \\
\hline \multicolumn{4}{|l|}{ Days in fields } \\
\hline No & 14.1 & 1.0 & \\
\hline Yes & 12.5 & 0.66 & $0.48-0.90$ \\
\hline \multicolumn{4}{|l|}{ Evening in house } \\
\hline No & 23.4 & 1.0 & \\
\hline Yes & 12.6 & 0.66 & $0.43-1.02$ \\
\hline \multicolumn{4}{|c|}{ Household-level variables: } \\
\hline \multicolumn{4}{|c|}{ Water around house } \\
\hline Yes & 12.2 & 1.0 & \\
\hline No & 9.4 & 0.63 & $0.46-0.86$ \\
\hline \multicolumn{4}{|c|}{ Domestic animals } \\
\hline Yes & 12.3 & 1.0 & \\
\hline No & 9.8 & 0.79 & $0.60-1.04$ \\
\hline \multicolumn{4}{|c|}{ Distance to irrigated fields } \\
\hline $0-600 \mathrm{~m}$ & 9.4 & 1.0 & \\
\hline $60 \mathrm{I}-800 \mathrm{~m}$ & 13.9 & 1.88 & $1.32-2.67$ \\
\hline$>800 \mathrm{~m}$ & II.I & 1.50 & $1.01-2.21$ \\
\hline \multicolumn{4}{|c|}{$\%$ irrigated field in $200 \mathrm{~m}$} \\
\hline $0 \%$ & 11.7 & 1.0 & \\
\hline$>0 \%$ & 10.4 & 1.38 & $0.95-2.00$ \\
\hline
\end{tabular}

a $s c=$ recent dengue infection; $\mathrm{aOR}=$ adjusted Odds ratio; $95 \%-\mathrm{Cl}=95 \%$ Confidence Interval.

have a more important role in dengue infection prevention than previously thought, as indicated by its significant protective effect.

Household level effects included the type of housing in Ban Pa Nai and Mae Hia. People living in houses made of a combination of materials had a lower risk; the causal link behind this variable is not clear. In Ban Pang the significant household variables are related to the vector ecology. Houses with no water containers around the house, therefore providing no breeding sites, had a lower risk. Houses with no domestic animals had a lower risk as well. Animals could provide alternative blood sources. However, Aedes mosquitoes are highly anthropophilic. The presence of animals might enhance the attractivity of the house, but mosquitoes would only bite humans.

\section{Landscape and land-cover variables}

Land cover may be an important risk determinant for infection, depending on whether the landscape surrounding a person supports a large mosquito population or not, mostly by providing breeding habitats. In this study, we attempted to directly relate landscape features with the risk of dengue infection, by-passing a quantification of mosquito population in different habitats. The results indicate that land cover and spatial organization of villages and surrounding landscape play a role in dengue infection. However, great care in interpreting results 
Table 5: Three-level analyses to identify determinants for recent dengue infection in Mae Hia, northern Thailand.

\begin{tabular}{|c|c|c|c|}
\hline & $\% s c^{a}$ & $\mathrm{aOR}^{\mathrm{a}}$ & $95 \% \mathrm{Cla}^{\mathrm{a}}$ \\
\hline ICC individuals & & $<0.0001$ & \\
\hline ICC households & & $<0.0001$ & \\
\hline \multicolumn{4}{|l|}{ Time (survey) } \\
\hline May 2002 & 6.9 & 1.0 & \\
\hline September 2002 & 26.7 & 4.76 & $3.28-6.91$ \\
\hline May 2003 & 1.4 & 0.18 & $0.08-0.39$ \\
\hline September 2003 & 2.7 & 0.31 & $0.16-0.57$ \\
\hline \multicolumn{4}{|l|}{ Individual-level variables: } \\
\hline \multicolumn{4}{|l|}{ Using abate } \\
\hline No & 5.8 & 1.0 & \\
\hline Yes & 9.7 & 1.42 & $0.99-2.02$ \\
\hline \multicolumn{4}{|l|}{ Bitten during day time } \\
\hline Never & 7.2 & 1.0 & \\
\hline Sometimes & 8.9 & 1.25 & $0.88-1.78$ \\
\hline Often & 8.6 & 1.71 & $0.90-3.26$ \\
\hline \multicolumn{4}{|l|}{ Household-level variables: } \\
\hline \multicolumn{4}{|l|}{ Housing } \\
\hline Wood or bamboo & 7.6 & 1.0 & \\
\hline Stone & 7.8 & 1.27 & $0.79-2.04$ \\
\hline Combination of stone, wood/bamboo & 10.3 & 1.90 & $1.16-3.10$ \\
\hline \multicolumn{4}{|l|}{ Distance to orchards } \\
\hline $0-150 \mathrm{~m}$ & 9.6 & 1.0 & \\
\hline $151-300 \mathrm{~m}$ & 8.8 & 0.72 & $0.49-1.04$ \\
\hline$>300 \mathrm{~m}$ & 7.1 & 0.47 & $0.28-0.79$ \\
\hline \multicolumn{4}{|l|}{ Distance to water bodies } \\
\hline $0-500 \mathrm{~m}$ & 5.9 & 1.0 & \\
\hline $500-1300 \mathrm{~m}$ & 8.3 & 2.26 & $1.32-3.87$ \\
\hline$>1300 \mathrm{~m}$ & 10.5 & 2.66 & $1.49-4.75$ \\
\hline \multicolumn{4}{|l|}{$\%$ bare soils in $200 \mathrm{~m}$} \\
\hline $0 \%$ & 9.8 & 1.0 & \\
\hline $1 \%$ & 7.8 & 0.74 & $0.49-1.11$ \\
\hline$>1 \%$ & 7.3 & 0.55 & $0.38-0.79$ \\
\hline \multicolumn{4}{|c|}{$\%$ village area with vegetation in $200 \mathrm{~m}$} \\
\hline $0-2 \%$ & 8.4 & 1.0 & \\
\hline $3-8 \%$ & 8.3 & 0.73 & $0.49-1.10$ \\
\hline$>8 \%$ & 8.7 & 0.54 & $0.68-0.79$ \\
\hline
\end{tabular}

a sc = recent dengue infection; $\mathrm{aOR}=$ adjusted Odds ratio; $95 \%-\mathrm{Cl}=95 \%$ Confidence Interval.

related to land cover is needed. In Mae Hia, results highlight the role of land cover as a source of breeding habitat. Orchards often contain a variety of artificial water containers, which would offer alternative breeding sites for Aedes while improved housing conditions offer less breeding habitats around houses. Proximity to orchards increased the risk of infection in Mae Hia, whereas the presence of bare soils around the house decreased that risk. Bare soils are unsuitable for Aedes breeding. Other variables were not easy to interpret, such as the distance to water bodies. This could be a proxy for other features, including socio-economic variables. The variable related to the importance of village area with dense vegetation does not correspond to breeding preferences of Aedes mosquitoes but could be related to housing type or quality.

Location of possible clusters and landscape spatial pattern should be considered together when interpreting the land cover effects on infection risk. In Ban Pa Nai, the apparent contradiction of the effect of proximity to irrigated field decreasing the risk on the one hand and of the proportion of irrigated field effect (decreasing the risk with increasing proportion) on the other hand is caused by the particular spatial configuration of the villages and the location of the cluster. The cluster is indeed located near the edge of the village, but with few irrigated fields around. Irrigated fields offer no suitable breeding habitat for Aedes and 


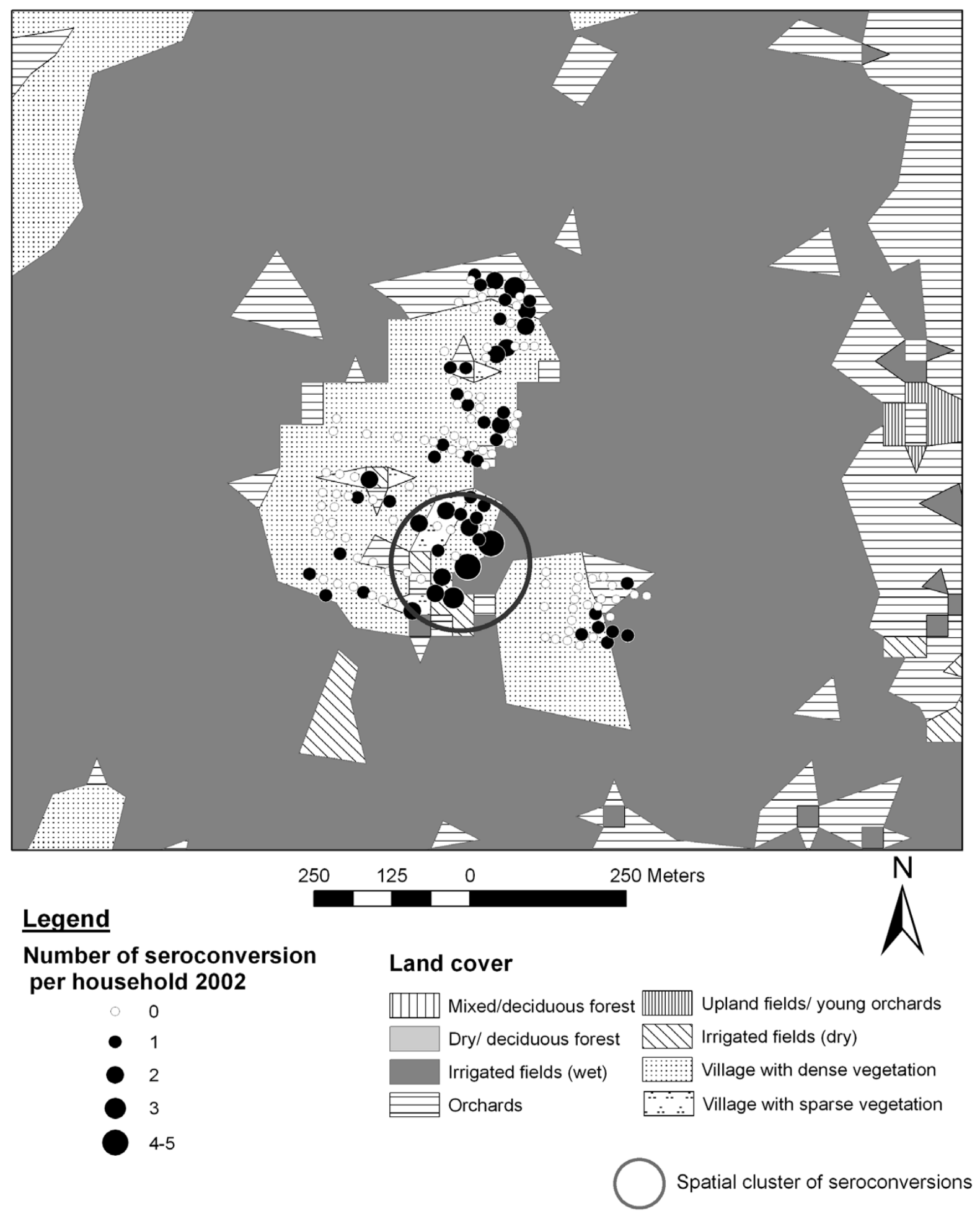

\section{Figure 5}

Land cover, recent dengue infection in 2002 and spatial cluster in Ban Pa Nai. 


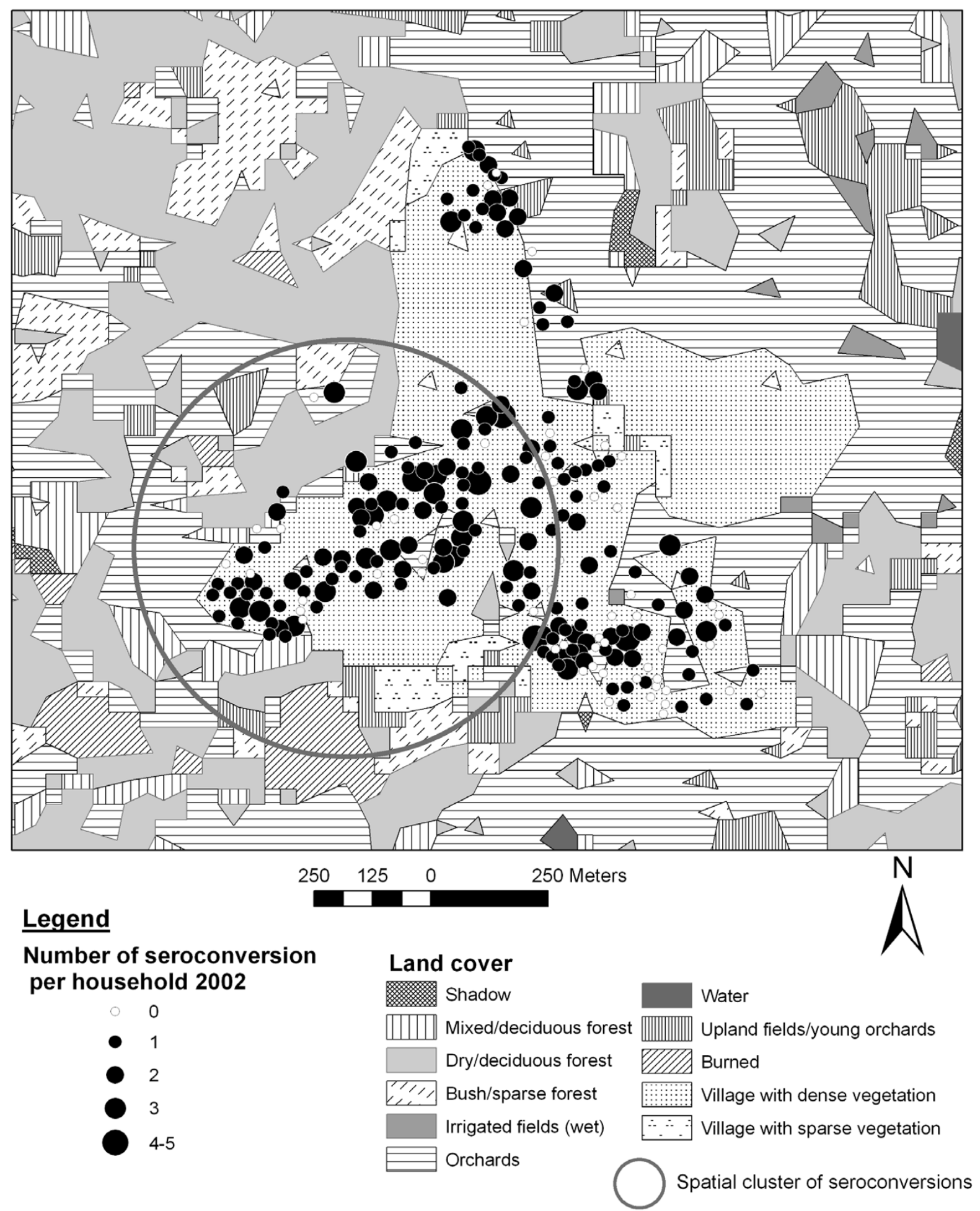

Figure 6

Land cover, recent dengue infection in 2002 and spatial cluster in Ban Pang. 


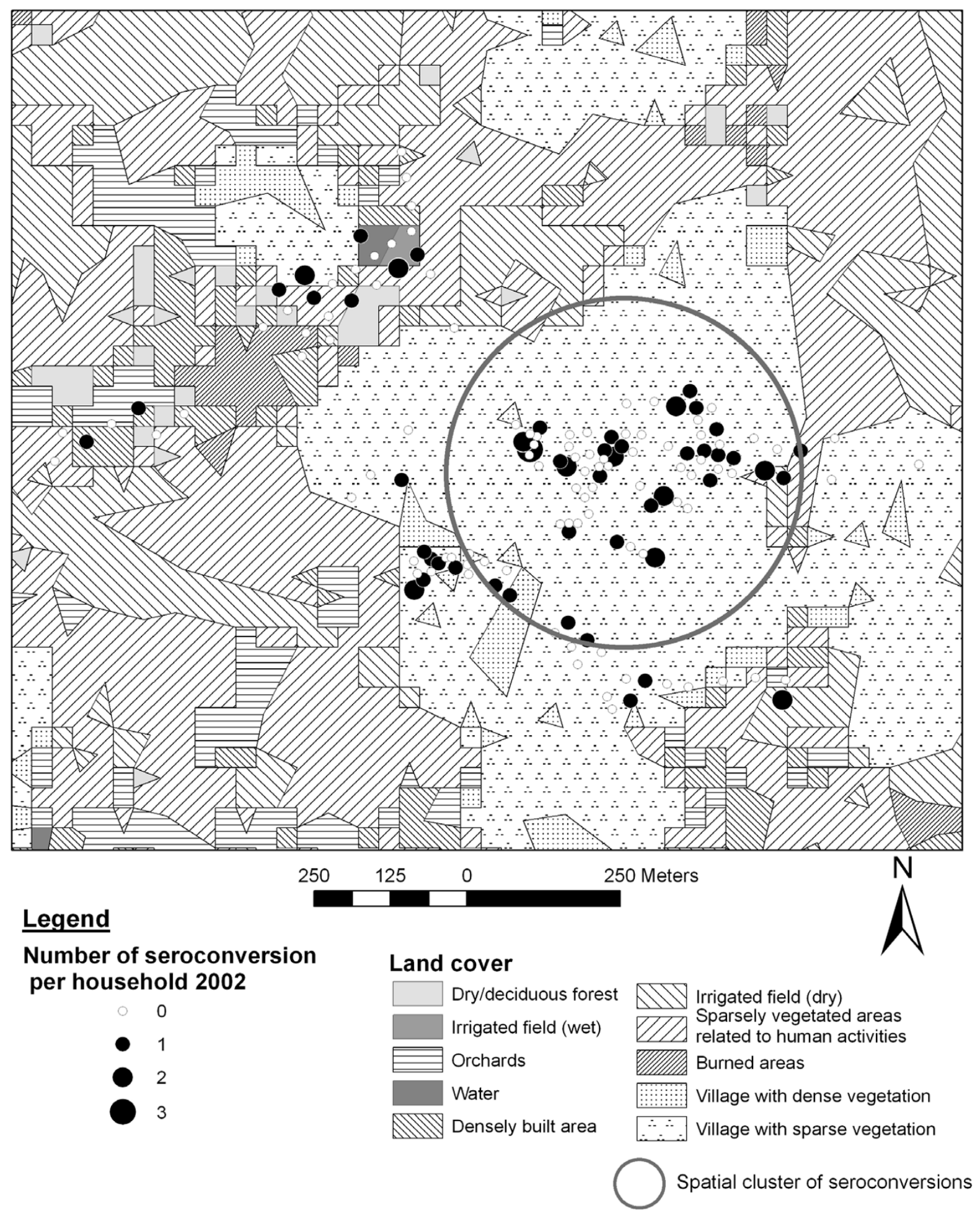

\section{Figure 7}

Land cover, recent dengue infection in 2002 and spatial cluster in Mae Hia. 
therefore do not act as a source of mosquitoes, whereas village areas do.

A similar effect was observed in Ban Pang: the location of the cluster further away from the irrigated fields explains the effect of distance to irrigated fields (wet), while a higher risk for people living with a higher proportion of irrigated fields around possibly proxies another effect. This variable is significantly correlated with none of the other landscape characteristics. The orchards found in this area are much older and possibly influence mosquito breeding and transmission differently than younger orchards. These houses are also located close to the main road.

Our results indicate that land cover needs to be considered in dengue transmission dynamics, especially landcover types providing breeding habitats, but that varying local conditions will strongly influence the importance and role of the landscape on the risk of infection. Previously unused habitats, such as orchards, might be found in increasingly important land-cover types in a context of housing improvement as observed in the suburbs of Chiang Mai. Agricultural land covers can no longer be ignored in dengue control given the rising prevalence of dengue in rural areas. Improved knowledge on vector ecology, behavior and dispersal, especially regarding Ae. albopictus, and on the role of this vector in dengue transmission would greatly improve interpretation of land cover effects [Vanwambeke et al., forthcoming]. GIS can be a useful tool since it integrates spatial and environmental variables and locates cases of infection to identify high-risk areas and environmental determinants. The spatial configuration of villages needs to be considered when considering spatial patterns of infection and a thorough knowledge of vector ecology can also help in understanding the observed patterns.

\section{Cluster analyses}

The peak incidence of recent dengue infection took place in 2002 for all study sites, corresponding with the temporal cluster identified by analysis of spatial and temporal clustering. During this peak year, some areas within a site were more affected than others, indicating variation in local infection patterns. As was shown in the multi-level analysis, the determinants for recent dengue infection differed between sites and, as shown by the spatial clusters, possibly within sites. Moreover, the intraclass correlation for individual and household level was very low, thus the largest part of variance was explained by factors varying over time: conditions might have been more favorable in 2002. These results show that the focal nature of the infection does not only exist for symptomatic dengue cases but also occurs in asymptomatic infections, and indicates the relevance of studying asymptomatic dengue infection.
The clusters could also relate to host-pathogen dynamics. A radiating pattern emanating from Bangkok has been described by others $[5,33,34]$. The radiating pattern in symptomatic dengue cases is thought to reflect host-pathogen population dynamics [35], but what causes the wave pattern of asymptomatic infections is unknown. It might be related to changes in the year-round circulation of dengue virus [36,37], since infection took place both between May and September and between September and May. Serotypes were not measured in this study, and the peak of infections in 2002 observed in our study did not correspond with the peak in symptomatic dengue cases that occurred in 2001. National data showed that the main serotype in 2000 and 2001 was serotype 1, whereas in 2002 serotype 2 was the main serotype detected (Ministry of Public Health, Dept. of Disease Control). The percentage of asymptomatic or lightly symptomatic infections was high but varied over the years as was shown by others $[10,14]$. The focal nature of dengue in space and time was observed in other studies and could be related to clusters of Aedes [34,38,39].

\section{Limitations of the study}

Factors determining the spatial and temporal clustering were not specifically investigated in this study, but would deserve further work. Clustering could have several origins: host-pathogen dynamics, national scale radiating patterns of cases, mosquito-vector ecology, or individual or household-level risk determinants. Such a study would however require a different data collection approach.

Note also that no household-level entomological data were collected as part of this study.

\section{Conclusion}

Our study showed that the focal nature of dengue not only appears in symptomatic dengue cases, but also exists for asymptomatic dengue infections. Environmental variables were significant, but the interpretation of their effect needs to combine several types of information such as the existence and location of clusters and vector ecology. The great variation of determinants for recent dengue infection in space and time should be taken into account when designing local dengue control programs.

\section{Authors' contributions}

Sophie O. Vanwambeke derived land-cover maps from the Landsat image and derived land-cover variables for the surveyed households. She participated in analyzing the dengue infection data. She analyzed weather patterns in the survey years as presented. She led the writing of the paper. Birgit H.B. van Benthem directed the epidemiological data collection, and digitized the village maps. She participated in analyzing the dengue infection data. She carried out the three-level analysis including individuals, 
households and all surveys as presented, and the cluster analysis on the longitudinal data. SOV and BvB interpreted the results together and then with the other coauthors. Nardalada Khantikul organized, supervised and participated in the collection of the dengue data. Chantal Burghoorn-Maas carried out the laboratory analysis of blood samples. Kamolwan Panart supervised and participated in the collection of the dengue data. Linda Oskam participated in conceptualizing the collection of the dengue data and analysis, in interpreting results, and provided input on the paper. Eric F. Lambin participated in conceptualizing the land-cover data analysis, in interpreting results, and provided input on the paper. Pradya Somboon helped designing and supervising the collection of the dengue data, in interpreting results, and provided input on the paper.

\section{Financial support}

This study was financially supported by EU grant QLRT1999-31787, provided within the Quality of Life and Management of Living Resources Programme (19982002).

\section{No conflict of interest to declare.}

\section{Acknowledgements}

We thank all participants of the epidemiological dengue survey for their participation, and the staff of the Vector Borne Disease Control (VBDC) units and VBDC office no. 2 as well as the local public health volunteers for their collaboration. We thank Ralph E. Harbach from The Natural History Museum, London, for his review of the mosquito taxonomy.

\section{References}

I. WHO-Regional Office South-East Asia website [http:// w3.whosea.org/en/Section I0/Section332 I 104.htm]

2. Ministry of Public Health, Division of Epidemiology: Annual epidemiological surveillance report. 1989:67-74.

3. Ministry of Public Health, Department of Communicable Disease Control: Communicable Disease Control in Thailand; 2000.

4. Cummings DAT, Irizarry RA, Huang NE, Endy TP, Nisalak A, Ungchusak K, Burke DS: Travelling waves in the occurrence of dengue haemorrhagic fever in Thailand. Nature 2004, 427:344-347.

5. Vazeille M, Rosen L, Mousson L, Failloux AB: Low oral receptivity for Dengue type 2 viruses of Aedes albopictus from Southeast Asia compared with that of Aedes Aegypti. Am J Trop Med Hyg 2003, 68:203-208.

6. Reinert JF, Harbach RE, Kitching IJ: Phylogeny and classification of Aedini (Diptera: Culicidae), based on morphological characters of all life stages. Zool J Linn Soc 2004, I 42:289-368.

7. Gubler DJ: Aedes albopictus in Africa. Lancet Infect Dis 2003, 3:75I-752.

8. Kittayapong P, Strickman D: Distribution of container-inhabiting Aedes larvae (Diptera: Culicidae) at a dengue focus in Thailand. I Med Entomol 1993, 30:60I-606.

9. Gratz NG, Knudsen $A B$ : The rise and spread of dengue, dengue haemorrhagic fever and its vectors, 1950-1990. Den Bull 1997, 2I:I23-127.

10. Endy TP, Chunsuttiwat S, Nisalak A, Libraty DH, Green S, Rothman $A L$, Vaughn AL, Ennis FA: Epidemiology of inapparent and symptomatic acute dengue virus infection: a prospective study of primary school children in Kamphaeng Phet, Thailand. Am J Epidemiol 2002, I 56:40-5I.

II. Strickman D, Sithiprasasna R, Kittayapong P, Innis BL: Distribution of Dengue and Japanese Encephalitis among children in rural and suburban thai villages. Am J Trop Med Hyg 2000, 63:27-35.
12. Muttitanon W, Kongthong P, Kongkanon C, Yoksan S, Nitatpattana N, Gonzales JP, Barbazan P: Spatial and temporal dynamics of Dengue Hemorrhagic Fever epidemics, Nakhon Pathom province, Thailand, 1997-200I. Den Bull 2004, 28:35-43.

13. van Benthem BHB, Vanwambeke SO, Khantikul N, Burghoorn-Maas C, Panart K, Oskam L, Lambin EF, Somboon P: Spatial patterns of and risk factors for seropositivity for dengue infection. $\mathrm{Am} J$ Trop Med Hyg 2005, 72:20I-208.

14. Burke DS, Nisalak A, Johnson DE, Scott TM: A prospective study of dengue infections in Bangkok. Am J Trop Med Hyg 1988, 38: $172-180$.

15. Vanwambeke S: Impacts of land-use change on mosquitoborne diseases in Northern Thailand. In PhD thesis Université catholique de Louvain, Department of Geography; 2005.

16. van Benthem BHB, Khantikul N, Panart K, Kessels PJ, Somboon P, Oskam L: Knowledge and use of prevention measures related to dengue in northern Thailand. Trop Med Int Health 2002, 7:993-1000.

17. Groen J, Koraka P, Velzing J, Copra C, Osterhaus ADME: Evaluation of six immunoassays for detection of dengue virus-specific immunoglobulin $\mathbf{M}$ and $\mathbf{G}$ antibodies. Clin Diagn Lab Immunol 2000, 7:867-87I.

18. WHO: Dengue haemorrhagic fever: diagnosis, treatment, prevention and control Geneva: World Health Organisation; 1997.

19. Koraka P, Suharti C, Setiati TE, Mairuhu ATA, Van Gorp E, Hack CE, Juffrie M, Sutaryo J, Van Der Meer GM, Groen J, Osterhaus ADME: Kinetics of dengue virus-specific serum immunoglobulin classes and subclasses correlate with outcome of infection. J Clin Microb 200I, 39( I 2):4332-4338.

20. Kreft I, De Leeuw J: Introducing multilevel modeling London: SAGE Publications; 1998.

21. Gibbons RD, Hedeker D: Random effect probit and logistic regression models for three-level data. Biometrics 1997, 53: I527-1537.

22. Snijders TAB, Boskers RJ: Multilevel analysis. An introduction to basic and advanced multilevel modeling London: SAGE; 1999.

23. Goldstein H: Multilevel statistical models 2nd edition. London: Arnold; 1995.

24. Kuldorff M, Nagarwalla N: Spatial disease clusters: detection and inference. Stat Med 1995, 14:799-8I0.

25. Chadee DD, Martinez R: Landing periodicity of Aedes aegypti with implications for dengue transmission in Trinidad, West Indies. J Vector Ecol 2000, 25: I58-163.

26. Selvaraj Pandian R, Dwarakanath SK: The biting activity rhythm in Aedini mosquitoes of Madurai. Comp Physiol Ecol 1992, 17:66-70.

27. Ali M, Wagatsuma $Y$, Emch M, Breiman RF: Use of a geographic information system for defining spatial risk for dengue transmission in Bangladesh: role of Aedes albopictus in an urban outbreak. Am J Trop Med Hyg 2003, 69:634-640.

28. Gratz NG: Critical review of the vector status of Aedes albopictus. Med Vet Entomol 2004, 1 8:215-227.

29. Eamchan P, Nisalak A, Foy HJ, Charoensook OA: Epidemiology and control of dengue virus infections in Thai villages in 1987. Am J Trop Med Hyg I989, 4I(I):95-I0I.

30. Thomson M, Connor S, Bennett S, D'Alessandro U, Milligan P, Aikins $M$, Langerock P, Jawara M, Greenwood B: Geographical perspectives on bednet use and malaria transmission in The Gambia, West Africa. Soc Sc Med 1996, 43(I): I0I-II2.

31. Rosenberg R, Andre RG, Somchit L: Highly efficient dry season transmission of malaria in Thailand. Trans Royal Soc Trop Med Hyg 1990, 84:22-28.

32. Thavara $U$, Tawatsin $A$, Chansang $C$, Kong-ngamsuk W, Paosriwong $\mathrm{S}$, Boon-Long J, Rongsriyam Y, Komalamisra N: Larval occurrence, oviposition behavior and biting activity of potential mosquito vectors of dengue on Samui Island, Thailand. J Vect Ecol 200I, 26(2): I72-180.

33. Hay SI, Myers MF, Burke DS, Vaughn DW, Endy T, Nisalak A, Shanks GD, Snow RW, Rogers DJ: Etiology of interepidemic periods of mosquito-borne diseases. Proc Nat Acad Sci 2000, 97:9335-9339.

34. Strickman D, Kittayapong P: Dengue and its vectors in Thailand: introduction to the study and seasonal distribution of Aedes larvae. Am J Trop med Hyg 2002, 67:247-259.

35. Ferguson N, Anderson R, Gupta S: The effect of antibodydependent enhancement on the transmission dynamics and persistence of multiple-strain pathogens. Proc Natl Acad Sci 1999, 96:790-794. 
36. Nisalak A, Endy TP, Nimmannitya S, Kalayanarooj S, Thisayakorn U, Scott RM, Burke DS, Hoke CH, Innis BL, Vaughn DW: Serotypespecific dengue virus circulation and dengue disease in Bangkok, Thailand from 1973 to 1999. Am J Trop Med Hyg 2003, 68:191-202.

37. Porter KR, Beckett CG, Kosasih H, Tan RI, Alisjahbana B, Rudiman PIF, Widjaja S, Listiyaningsih E, Ma'Roef CN, Mcardle JL, Parwati I, Sudjana P, Jusuf H, Yuwono D, Wuryadi S: Epidemiology of dengue and dengue hemorrhagic fever in a cohort of adults living in Bandung, West Java, Indonesia. Am J Trop Med Hyg 2005, 72:60-66.

38. Tran A, Deparis $X$, Dussart P, Morvan J, Rabarison P, Remy F, Polidori L, Gardon J: Dengue Spatial and Temporal Patterns, French Guiana, 2001. Emerg Infect Dis 2004, 10:61 5-621.

39. Getis A, Morrison AC, Gray K, Scott TW: Characteristics of the spatial pattern of the dengue vector, Aedes aegypti, in Iquitos, Peru. Am J Trop Med Hyg 2003, 69:494-505.

Publish with Bio Med Central and every scientist can read your work free of charge

"BioMed Central will be the most significant development for disseminating the results of biomedical research in our lifetime. "

Sir Paul Nurse, Cancer Research UK

Your research papers will be:

- available free of charge to the entire biomedical community

- peer reviewed and published immediately upon acceptance

- cited in PubMed and archived on PubMed Central

- yours - you keep the copyright

Submit your manuscript here:

http://www.biomedcentral.com/info/publishing_adv.asp
BiolMedcentral 